\title{
Native Language Interference in English L2 Word Recognition and Word Integration Skills
}

\author{
Nazanin Biglari \\ Vrije Universiteit Brussel (VUB), Brussels, Belgium \\ Esli Struys \\ Vrije Universiteit Brussel (VUB), Brussels, Belgium
}

\begin{abstract}
The current study was planned to investigate the interference of the native language in English word recognition and word integration skills in L1 speakers of French and Persian. The participants of the study were 48 intermediate and upper intermediate native Persian and French-speaking EFL learners studying in VUB and ULB universities in Brussels, Belgium. All in all, based on the results of ANCOVA, there was a strong and positive relationship between EFL learners' word recognition and word integration skills and their L1(first language). The RT (reaction time) resulting from the LDT (lexical decision task) showed that the Persian EFL participants were able to outperform French EFL participants, though Persian and English are orthographically and typologically distant languages. On the other hand, in a word integration task, French participants showed superiority over Persian participants in the direct object reading time that emphasized the positive aspect of $\mathrm{L} 1$ interference as facilitation.
\end{abstract}

Index Terms - mother tongue, mother tongue interference, reading comprehension, word integration, word recognition

\section{INTRODUCTION}

One of the major issues in today's world is bilingualism and multilingualism that called the attention of lots of researches. Firstly, as (Bhatia \& Ritchie, 2008) acknowledged, the world's approximately 5,000 languages are spoken in the world's 200 sovereign states, meaning that communication between citizens in several countries calls for robust bilingualism/multilingualism. Considering bilingualism involving English, the statistics indicate that more than $41 \%$ or 235 million of the about 570 million English-speaking citizens worldwide were bilingual in English and some other languages (Bhatia \& Ritchie, 2008).

According to Crystal (2012), English today has a special standing in at least 70 countries and is the most commonly spoken international language in more than 100 other nations, and as (Burchfield, 1985) announced, English has been a lingua franca all over the world. Hence the techniques and strategies used in the teaching of English have gained popularity due to the requirements of English language learners, in particular English as a second language (ESL) and English as a foreign language (EFL) (Turker \& Selcuk, 2009).

English is learned by four primary skills: listening, speaking, reading, and writing (Turker \& Selcuk, 2009). Reading is commonly referred to as the most critical of the four language skills of ESL / EFL learners (Gu, 2003). In addition, reading comprehension studies have shown the importance and incidence of word-level processing capabilities used in fluent reading or text processing (Just \& Carpenter, 1980).

A large amount of the first-language (L1) literature specifically shows that word recognition (as a pre-lexical mechanism refers to the ability to identify the form of written (i.e. orthographic) term or lexical entity that allows the sense of the phrase, structural / syntactic information, and other relations of pragmatics or environment knowledge (Fender, 2001, 2003)), and word integration processes (i.e. combining terms into broader units of context at the sentence and clause level) are the most commonly used of the cognitive and linguistic mechanisms utilized in text processing (Grabe, 1988).

Therefore, as $(\mathrm{Zu}, 2009)$ reported, scholars, teachers and those interested in foreign language learning are paying special attention to the development of foreign language vocabulary and lower-level processing. In addition, (Gass, 1999) declared that learning a second language means learning its vocabulary, suggesting that knowing a lexical item means knowing several things. Vocabulary literacy is not an end of itself; it is undertaken to enable learners listen, talk, read and compose more efficiently (Nation, 2003). Similarly, research with relatively competent second-language $/$ English as a second-language (L2 / ESL) speakers demonstrates that phrase-level communication capacities, like word recognition and word integration skills, are the most widely employed perceptual and linguistic processes for reading and text processing L2 / ESL (Frenck-Mestre \& Pynte, 1997).

There are, however, some important differences between developing word-level processing skills at L1 and developing word-level processing skills at L2/ESL, especially for those who learn L2/ESL literacy skills during adolescence and later (Fender, 2003). First language intervention plays a significant part in the learning of the second 
language (Kellerman, 1986). The L1 effect stems from the conscious or unconscious opinion of a learner that linguistic elements are identical in both the native and target languages, and it was believed that the learners' L1 habits had clashed with their L2 habits (Odlin, 1989).

Although there is a general understanding that transition happens mostly at the level of the sound system, primarily production and pronunciation, cross-linguistic experiments investigating word order transmission have found that morphemes and other syntactic structures of higher-order are more frequent than phonology-related transfer studies (Aquil, 2012). In other words, the study evidence shows that word-level processing skills at L1 tend to be a major factor interfering with and affecting the production of word-level processing skills at L2/ESL (Koda, 2000). Hence, ESL learners with typologically diverse L1 contexts can have markedly specific problems and thus different needs in learning fluent ESL text processing skills at word-level (Fender, 2003).

\section{RESEARCH PROBLEM}

First language intervention plays a significant part in the learning of a second language (Kellerman, 1986). Based on several studies performed by linguists, it was hypothesized that the typologically distinct languages have an impact on L2 learning processes. Ironically, it was proposed that the gap between languages, influences the rate of acquisition of L2 rather than the forms of transition (Odlin, 1989). In other words, if you study a language that is normally different from your mother tongue, it takes more time to acquire L2 compared to a language that is like your L1 (Hakuta \& McLaughlin, 1996b).

Additionally (Inoue, 1996) conducted a study by using a model of the neural network indicated that the difference between languages affects the learning rate: the greater the distance between two languages, the longer it takes to learn. The model also showed an association of the language gap and the learning form. (Schachter, 1983) in his study expanded the notion of transferring to include any prior information that L2 learners have, including "imperfect" information of L2 learners. Shift applies not only to the negative factors (interference) on L2 learning but also to the positive influences (facilitation) (Hakuta \& McLaughlin, 1996b).In another study (Frost, Katz, \& Bentin, 1987) concluded that the L1's structural features typically tend to form the related L1 processing procedures, like the L1 orthography system, however, the creation of the underlying L1 word recognition skills are influenced in specific ways.

The result of a study by (Bates, 1999) was that the linguistic characteristics of the L1 phrases and clause systems form the underlying L1 word integration or sentence parsing methods. Reading and psycholinguistic studies suggest that fluent and effective comprehension requires the integration of knowledge from a variety of text processing capabilities at lower and higher rates. Accordingly, readers simultaneously process knowledge on the letter/phoneme, term, phrase/clause, paragraph, local cohesion, subject, pragmatic, and discourse structure to interpret and understand texts (Grabe, 1988). As language skills such as word recognition or word integration automatically operate, more text information may be processed and inserted into the working memory (Just \& Carpenter, 1980). In other words, if lowerlevel word-level computing abilities are unreliable or underdeveloped, reading speed and/or comprehension would be negatively affected because less knowledge will be processed and incorporated into the working memory at any moment (Fender, 2003).

The efficient process of decoding abilities and word-level reading is, of course, crucial for fluency and comprehension in reading skills of L1 and L2/ESL (McDonald, 2000). While there has been little work on online word integration and sentence comprehension in L2/ESL, initial research in this field indicates that professional L2/ESL speakers acquire word integration skills quite close to native speakers (Bernhardt, 1987). There are indications that L1 word integration processes influence and form the creation of L2/ESL word integration processes, especially in adolescents who acquire L2/ESL (Fender, 2003). The result of a study by (Fender, 2003) on EFL learners of typologically distant languages, Japanese-English and Arabic-English indicated that the Japanese and Arabic participants have various word-level comprehension problems owing to the impact of their L1 on the understanding of word form and the process of word integration skills in L2.

In conclusion based on the importance of reading comprehension, and the limited number of studies on typologically distant languages, the present study was conducted to investigate the variation of the effect of L1 in typologically and orthographically distant and close languages on word-level processing skills (word recognition, and word integration) of adult intermediate and upper intermediate EFL learners of native Persian and French-speaking participants for developing EFL reading and text processing skills fluency and their use of lower-level word integration skills to integrate words into higher levels of sentences and clauses.

\section{SigNIFICANCE OF THE STUDY}

As reading comprehension is very significant in EFL learning, its growth as an ability will assume a vital importance in pedagogy (Mokhtari, 2014). Nevertheless, reading comprehension and vocabulary acquisition as the foundation block for reading comprehension has not been at the forefront of focus in education. By investigating areas of L1 interference of typologically and orthographically distant and close languages in reading comprehension and word integration skills of EFL learners, it will be possible for the syllabus designers, ministry of education, coursebook designers, and lesson planners to provide EFL and ESL instructors with certain ideas to be able to assist and support 
English learners to prevent language interference or to take advantage of the first language to improve the language learning especially reading comprehension. The current study is based on this assumption that language interference applies not only to the negative factors (interference) on L2 learning but also to the positive influences (facilitation) (Hakuta \& McLaughlin, 1996b). In other words, L1 may have some facilitation merits that can facilitate the process of a foreign or second language that must be considered.

Based on the above-mentioned results, we would expect that Persian and French EFL learners in the present study which is a crosslinguistic study on EFL learners of typologically distant (Persian-English) and close (French-English) languages, show some differences in EFL word recognition and word integration skills and performance due to their first language typological, orthographic, and structures differences.

\section{RESEARCH QUESTIONS}

For the purpose of the study the researcher considered the following questions:

1. Do Persian and French as native languages (L1) have a significant effect on intermediate and upper intermediate EFL learners' word recognition skills?

2. Do French-speaking bilingual intermediate and upper intermediate EFL learners with linguistically close native languages (French, English) outperform intermediate and upper intermediate linguistically distant native languages (Persian-English) EFL learners word recognition skills because of the similarities between both languages in this domain (word recognition)?

3. Do Persian and French native languages (L1) have a significant effect on intermediate and upper intermediate EFL learners' word integration skills?

4. Do French-speaking bilingual intermediate and upper intermediate EFL learners with linguistically close native languages (French-English) outperform intermediate and upper intermediate linguistically distant native languages (Persian-English) EFL learners word integration skills because of the similarities between both languages in this domain (word integration)?

\section{METHODOLOGY}

\section{A. Participants}

Participants for this study were 48 in total. 24 intermediate and upper intermediate female and male native Persianspeaking students studying at VUB university in Brussels and 24 intermediate and upper intermediate female and male native French-speaking students studying at ULB University, Brussels. The participants aged between 18 and 31 years were chosen based on convenience sampling since random selection was not possible for the researcher. All participants had passed the IELTS exam before varying from 4 to 6.5 .

To see whether the participants build a homogenous group in terms of their English proficiency, the researcher recorded the IELTS reading scores of the participants who were distributed into two groups, French-speaking and Persian speaking each containing 24 students. Those participants whose IELTS reading score ranged from 4 to 6.5 were chosen. It should be mentioned that based on the IELTS exam the students whose scores were between this range were considered as intermediate and upper intermediate level (Cambridge, n.d.). The 48 participants were assigned to two groups of French-speaking and Persian-speaking students. 24 Persian-speaking and 24 French-speaking. All 48 students took part in both tasks (word recognition and word integration tasks).

\section{B. Research Design}

In this quantitative study, the researcher investigated the interference of the native language in English word recognition and word integration skills in EFL intermediate and upper intermediate L1 speakers of French and Persian. Keeping this intention in mind, the researcher used a word recognition and a word integration task to measure the RT of both French and Persian groups.

\section{Instrumentation}

The following instruments were utilized to serve the purpose of the research study.

1) IELTS Test (International English Language Test)

To ensure that the language skills of the learners were homogeneous IELTS reading score which according to (Dooey \& Oliver, 2002) is one of the most used exams given by all participants have been recorded by the researcher. According to (Dooey \& Oliver, 2002) the IELTS exam is used as a measure of English proficiency for both global (international) and local ESL (English as a Second Language) pupils and the band score is out of 9.

In the IELTS exam, there are 4 modules reading, listening, speaking, writing, each module is out of 9 . The intermediate and upper intermediate band score is considered as 4 to 6.5 (Dooey \& Oliver, 2002).

2) Lexical Decision Task

To evaluate the word recognition skills of Persian-speaking and French-speaking EFL students an LDT (lexical decision task) was conducted by the researcher. The Lexical decision-making is one of the most employed testing approaches for the evaluation of word processing abilities in L1 research (Frost et al., 1987). Throughout this task, 
participants were to differentiate if each object was a word (i.e., lexical item) or not. In this task, participants required applying word recognition skills to distinguish lexical items from nonwords.

3) Sentence Reading Test

In order to measure word integration skills of the French and Persian-speaking EFL learners a sentence reading task was used. During this task 48 semantically high context and low context sentences were read by the participants on the computer. The participants read the sentences word by word and the pace was under the participants' control. Meanwhile, the computer recorded the direct object reading time of the participants. Reading times on the words represented not only word recognition systems, but also syntactic and semantic/conceptual systems that underlie word integration skills (Frenck-Mestre \& Pynte, 1997). Moreover, their sentence comprehension was measured by reading a series of sentences that semantically corresponded to the previous sentences that they have read, and the computer recorded their responses.

\section{Stimuli}

\section{1) Stimuli in Experiment 1 (Lexical Decision Task)}

Two key sets of stimulus items that were English words, namely consistent words, and inconsistent words were used by the researcher in the present study. Among these sets which were in total 80 words, the consistent category consisting of 20 words, was made of words that were four to six letters long. These words have been taken from Fender's research (2003). Moreover, according to (Fender, 2003), the consistent words were highly consistent based on grapheme-phoneme correspondences in the English orthography (e.g., game and letter). The second category (inconsistent words) consisted of 20 items containing four to six letters long as well. "For example, the word great is inconsistent in grapheme-phoneme mapping compared to other words that share the spelling pattern eat, such as heat, beat, meat, and cheat" (Fender, 2003, p. 298).

Two other categories of nonwords each consisting of 20 words were also included namely pseudowords, and nonpronounceable words. According to (Fender, 2003), pseudowords were the pronounceable nonwords (e.g., glir, zirp) following grapheme-phoneme English orthography. However, non-pronounceable words research were 20 items that violated the English spelling system and were not pronounceable such as dsae, mtli (Fender, 2003). Regarding the validity of the stimuli, since they were derived from Fender's research (2003) and were confirmed by Fender that the stimuli check the construct is intended to assess, they have been utilized by the researcher.

2) Stimuli in Experiment 2 (Lexical Decision Task)

The stimuli which were 48 sentences in this experiment were derived from Fenders' research (2003), and as Fender claimed in his research, all the words that have been used in the experimental sentences were among 1500 first words that EFL/ESL students learn. Additionally, Fender (2003) claimed that the verbs in 48 sentences were the verbs that were highly frequent in the Interchange text series by Richards (1997). Interchange series by Jack Richards is one of the most common books which are used for EFL/ESL students to learn the English language so it can be the poof of students' familiarity with the words in the experimental sentences (Fender, 2003). Word length was a significant consideration, and thus all the terms in the sentence before the direct object was one or two-syllable phrases (Fender, 2003).

(Fender, 2003) acknowledged that the other critical aspect was the form of the phrase, and all the experimental sentences had the same number of terms and composed of "subject noun + prepositional phrase + auxiliary will + main verb + the +objective noun + prepositional phrase" (Fender, 2003, p. 302) structure.

The experimental sentences in this task used transitive verbs involving a direct object noun phrase, and in this task the experimental sentences " require the participants to integrate or attach the direct object noun phrase as a verb complement in the verb phrase, then interpret the direct object according to the semantics of the verb " (Fender, 2003, p. 302). The experimental sentences were semantically from two categories called low context sentences and high context sentences.

As (Fender, 2003) claimed in his research:

The high context condition was created with a subject noun, a noun in a prepositional phrase, and a verb that were semantically/conceptually related to the object. That is, the subject noun, modifying prepositional phrase and the verb conjoined to provide a context with a high degree of semantic/conceptual association or plausibility for the direct object as in sentence 3 below:

3. The waiter in the kitchen will bring the food to the table.

4. The lady in the office will bring the food to the party (p. 310).

The sentence number 3 is semantically high context since "the subject noun, prepositional phrase and verb are conceptually related to the direct object noun" (Fender, 2003, p. 310), and the sentence number 4 is semantically low context since" no such comparable conceptual or semantic association exists among the sentence constituents preceding the direct object "(Fender, 2003, p. 310).

\section{E. Procedure}

1) Procedure in Experiment 1 (Lexical Decision Task)

The lexical decision task was run on an ASUS computer utilizing PsychoPy 3 software package. The presentation of the stimuli items was controlled by the software while the reaction time (RT) of the participants in choosing answers 
and their responses were also recorded by the software to be evaluated later. The participants began the task by viewing the instructions which have been given by the researcher orally before and some examples of word and nonword items were depicted on the monitor to avoid confusion.

Participants were told to click the correct button on their screen which means lexical item/word and for nonword items, the participants were told to press the left arrow. In addition, participants were advised to react as rapidly as possible yet accurately as possible. First, an asterisk emerged on the screen and lasted for 2 seconds, accompanied by the stimuli which were either word or nonword, consistent or inconsistent that randomly appeared on the screen.

In order to respond faster, the researcher told the participants to hold their middle finger on the right arrow and the index finger on the left arrow. The computer recorded the length of time every stimulus object turned into on the screen from the presentation onset to the lexical decision response.

2) Procedure in Experiment 2 (Sentence Reading Task)

This experiment went through different procedures such as, choosing the experimental sentences (stimuli), designing the task via PsychoPy 3 software, and running the test. The participants read 48 sentences that appeared randomly based on high semantic or low semantic context on the screen. Firstly, the participants were told how to the test, and in order to make sure that the EFL participants recognized the concept of the instructions appeared on the monitor again. The participants started the challenge by noticing the asterisk in the center of the screen and pressed the space bar and started the test to read the first word of the paragraph.

When the participants were prepared, they might proceed by pressing the key to scanning the first word. Solely the primary word of the sentence appeared on the screen within the sentence-initial position (i.e., the intense left-hand facet of the sentence). When the participants were ready for the next words, they pressed the key, and at that time, the primary word disappeared from the sentence-initial position and the second word within the sentence appeared in the second-word position in the sentence. Then, once the participants were prepared for successive words, they pressed the key. At that time the second word disappeared from the second abstraction position within the sentence and the third word appeared in the third sentence position. The participants had been informed before that the dot was a symbol of the end of the paragraph.

After finishing reading the sentence as they were instructed, they pressed the space bar and a true/false sentence appeared on the monitor. The participants were instructed to press the designated key (right arrow on the keyboard which means true) and the left arrow which implies false to respond based on the sentence that they have just read. From the moment the first word (stimulus) appeared on screen the participants' reading comprehension answers and their reaction time were recorded by the computer. Immediately after answering true/false sentences, an asterisk appeared on the monitor to initiate the next sentence. The participants continued this process till they completed all 48 sentences.

\section{F. Data Analysis}

In order to analyze the RT reaction time of the participants of both French and Persian groups, different statistical procedures have been carried out. In order to evaluate the data and control the effects of the covariate (IELTS reading score) ANCOVA (analysis of covariance) was utilized by the researcher.

\section{RESULTS}

\section{A. Word Recognition Analysis and Results}

A two-way repeated-measures analysis of covariance ANCOVA was used by the researcher to compare the word recognition RT of intermediate and upper intermediate French and Persian EFL learners. As the participants' levels of English proficiency were assumed to affect the groups' word recognition RT, the researcher considered IELTS reading scores as a covariate to adjust or remove the effects of language background in the analysis. Moreover, the participants' mother tongue (Persian, French) was the between-subjects variable in the analysis, and the RT was the dependent variable. Results for all statistical operations are listed below.

\section{B. Descriptive Statistics}

TABLE I.

DESCRIPTIVE StATISTICS OF GROUPS' REACTION TIME ON WORD RECOGNITION TEST

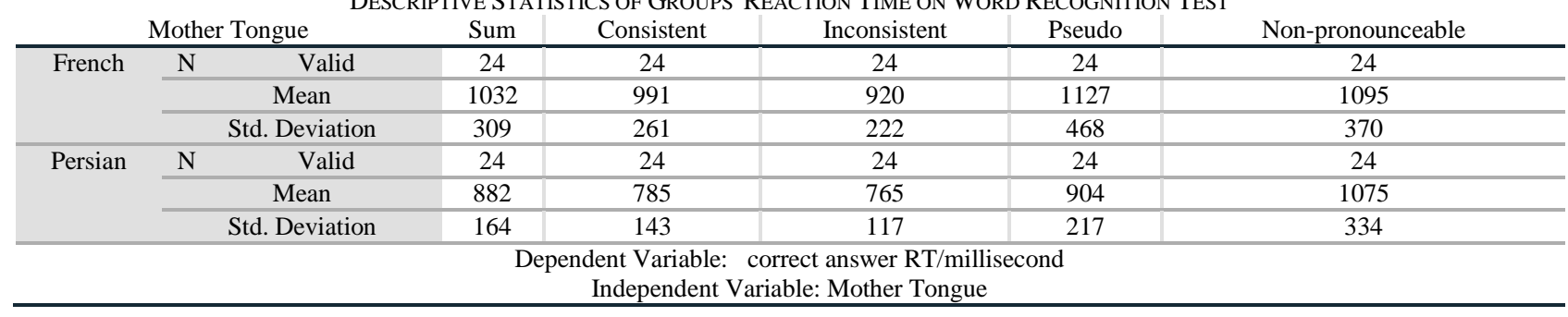


As it can be seen, Table I clearly shows the results of the EFL Persian and French learners' lexical decision tasks (word recognition test) RT per millisecond, in terms of descriptive parameters (mean, and standard deviation RT), across the four types of stimuli, consistent, inconsistent, pseudo, and non-pronounceable word conditions. As it is evident in Table I, the mean reaction time of the French group on the word recognition test was $1032 \mathrm{~ms}$ in total,991ms on consistent words, $920 \mathrm{~ms}$ on inconsistent words, $1127 \mathrm{~ms}$ on pseudowords and $1095 \mathrm{~ms}$ on non-pronounceable words, and they were $882 \mathrm{~ms}, 785 \mathrm{~ms}, 765 \mathrm{~ms}, 904 \mathrm{~ms}$ and $1075 \mathrm{~ms}$ respectively on the Persian group. Additionally, the standard deviation of the French group on the word recognition test was $309 \mathrm{~ms}$ in total, $261 \mathrm{~ms}$ in consistent words $222 \mathrm{~ms}$ in inconsistent words, $468 \mathrm{~ms}$ in pseudowords, and $370 \mathrm{~ms}$ in the non-pronounceable test, and they were $164 \mathrm{~ms}, 143 \mathrm{~ms}$, $117 \mathrm{~ms}, 217 \mathrm{~ms}$, and $334 \mathrm{~ms}$ respectively on the Persian group's word recognition test.

As (Field, 2016) acknowledged, recognizing that the average of one grouping is greater than that of another does not educate you enough to consider that there is a difference between the two categories. Therefore, the researcher conducted the ANCOVA test to make sure and check a disparity between the two groups' RT performance.

The results of the $2 \times 2$ (language group by word condition) repeated measures ANCOVA depicted a nearly significant main effect for language group, $(\mathrm{F}=3.275, \mathrm{p}=0.077>0.05)$. In addition, there is an important impact on word condition, so there was an interaction between the language group and word condition factors. The mean values across the four-word conditions (consistent, inconsistent, pseudo, and non-pronounceable) depicted (Figure 1) that the Persian EFL participants were able to process consistent, inconsistent, pseudo, and non-pronounceable words in a lexical decision task more rapidly than the French EFL participants, which is reflected in the overall group means (Table I ) for the Persian (882ms) and French (1032ms). Consequently, Persian participants demonstrated, 150-ms advantage over the French participants in total,206-ms across the consistent, 155-ms across inconsistent, 223-ms across pseudowords, and 20-ms across non-pronounceable word conditions. Surprisingly, the main difference (in major stimuli, consistent, and inconsistent words) in language group by word condition was mainly regarding consistent words as there was an advantage of 206-millisecond advantage over the French group. The result is illustrated in the following clustered bar chart.

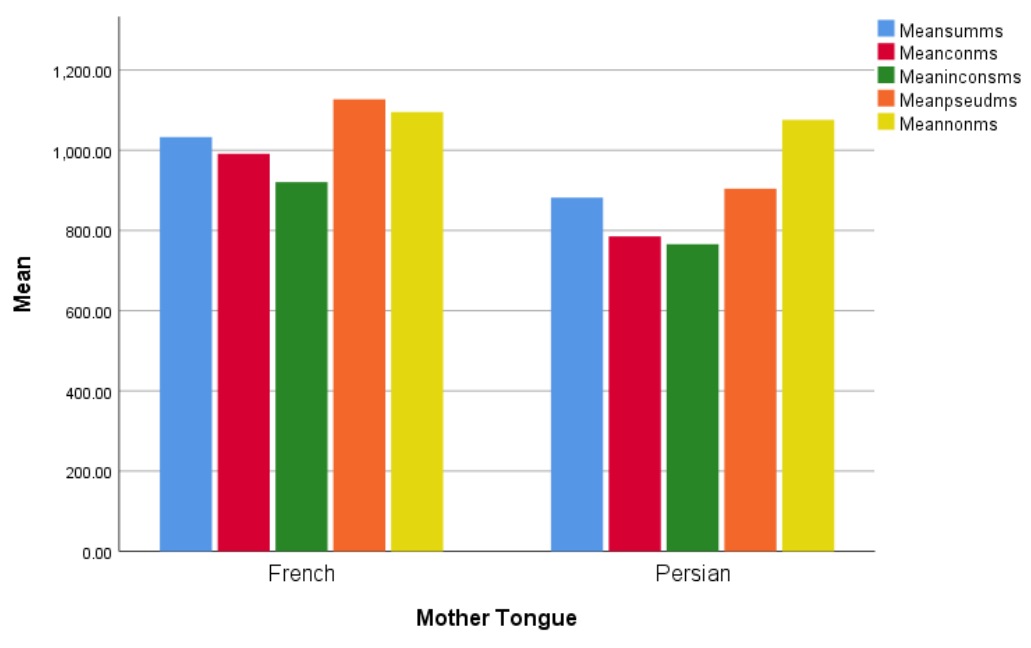

Figure 1. Mean Values (RT) Across the Four-Word Conditions

\section{Word Integration Analysis and Results}

To test the effect of L1 on student word integration skills, the researcher used the sentence reading task. In this test, just the direct object reaction time of the sentences that have been correctly replied was used to analyze and compare French and Persian groups RTs. The researcher applied A $2 \times 2$ (language group by semantic context) repeated measures ANCOVA to compare French and Persian groups word integration RTs. The participants' mother tongue (L1) was the between-subjects variable (independent variable), direct object reaction times as (dependent variables), IELS reading score as the covariate, and the semantic context condition with two semantic levels (high and low context) was used by the researcher in the analysis. The results of both statistical tasks are listed below.

\section{Word Integration Speed}


TABLE II.

DEsCRIPTIVE STATISTICS OF GROUPS' REACTION TIME ON WORD INTEGRATION TEST

\begin{tabular}{|c|c|c|c|c|c|}
\hline & Mother Tongue & & sum & High context & Low context \\
\hline \multirow[t]{4}{*}{ Persian-speaker } & \multirow[t]{2}{*}{$\mathrm{N}$} & Valid & 24 & 24 & 24 \\
\hline & & Missing & 0 & 0 & 0 \\
\hline & & Mean & 1595 & 688 & 2503 \\
\hline & & Std. Deviation & 213 & 241 & 263 \\
\hline \multirow[t]{4}{*}{ French-speaker } & \multirow[t]{2}{*}{$\mathrm{N}$} & Valid & 24 & 24 & 24 \\
\hline & & Missing & 0 & 0 & 0 \\
\hline & & Mean & 1416 & 497 & 2335 \\
\hline & & Std. Deviation & 184 & 187 & 222 \\
\hline
\end{tabular}

As it can be seen, Table II clearly shows the results of the EFL Persian and French learners' reading times on the direct objects in the reading task in terms of descriptive parameters (mean, and standard deviation across the two types of stimuli, high context, and low context.

As it is evident in Table II, the mean reaction time of the Persian group on the word integration test was $1595 \mathrm{~ms}$ in total, $688 \mathrm{~ms}$ in high context sentences, $2503 \mathrm{~ms}$ in low context sentences, and they were $1416 \mathrm{~ms}, 497 \mathrm{~ms}$, and $2335 \mathrm{~ms}$ respectively on the French group. Furthermore, the standard deviation of the French group on the word integration test was $184 \mathrm{~ms}$ in total, $187 \mathrm{~ms}$ in high context sentences, and $222 \mathrm{~ms}$ in low context sentences, and they were $213 \mathrm{~ms}, 241 \mathrm{~ms}$, and $263 \mathrm{~ms}$ respectively on the Persian group's word recognition test.

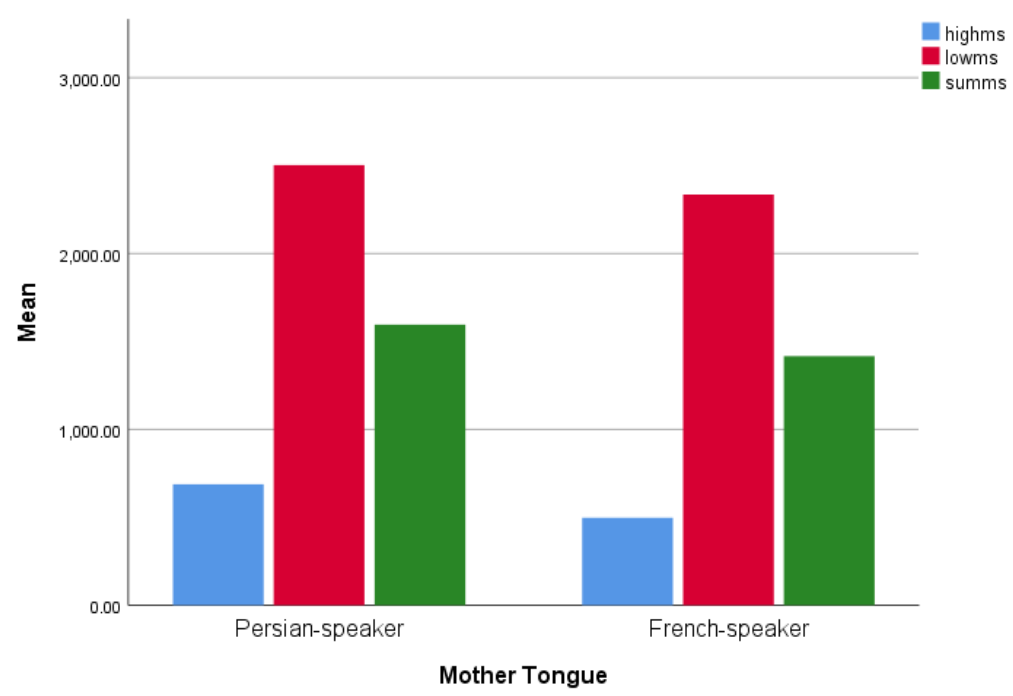

Figure 2. Mean Values Across the Two Semantic Context Conditions

The results of the $2 \times 2$ (language group by word condition) repeated measures ANCOVA depicted a highly significant main effect for language group, $(\mathrm{F}=8.129, \mathrm{p}=0.007<0.05)$. Therefore, Persian and French speakers did not process direct objects at the same rate. Additionally, there was a main effect for high context $(\mathrm{F}=7.966 \mathrm{p}=0.007<0.05)$ and low context $(\mathrm{F}=4.682, \mathrm{P}=0.036<0.05)$, so there was an interaction between the language group and context type.

The mean values across the two semantic context conditions depict (Table II) that the French EFL participants were able to integrate high context and low context direct objects more rapidly than the Persian EFL participants, which is reflected in the overall group means for the French (1416ms) and Persian (1595ms). Consequently, French participants demonstrated, $179 \mathrm{~ms}$ advantage over the Persian participants in total, 191ms across the high context, 168ms across low context semantic conditions. Additionally, it was concluded that both French and Persian groups' direct object reaction time was lower in high context and higher in low context as it is illustrated in Figure 2.

To be concluded, there was a main effect and interactive relationship between language group and context factors since high context with plausible direct objects were read faster than low context direct objects $(p=0.007<0.05)$.

\section{DISCUSSION}

\section{A. Addressing the Research Questions}

1) Addressing the First Research Hypothesis

In this research the first question explored was whether L1 has a significant effect on intermediate and upper intermediate EFL learners' word recognition skills. To answer this question, the present author tested two groups of participants, namely French and Persian groups. The results of the current study revealed that, that Persian and French- 
speaking participants have different word-level processing difficulties. Persian speakers exhibited word recognition advantage over French-speaking participants, indicating that French-speaking participant has less developed English word recognition skills than Persian-speaking participants in LDT (lexical decision task). Surprisingly this advantage was quite evident in consistent words. In conclusion, the null hypothesis was rejected.

2) Addressing the Second Research Hypothesis

The second question sought whether bilingual intermediate and upper intermediate native French-speaking EFL learners with linguistically and orthographically close native languages (French -English) outperform intermediate and upper intermediate native Persian-speaking participants with linguistically distant native languages (Persian-English) EFL learners in word recognition task owing to the similarities between the two languages in this area (word recognition). To answer this question, the present author tested two groups of participants, namely French and Persian. Based on the results of the current study, it could be concluded that the EFL French-speaking participants who did lexical decision task (word recognition task) did not go beyond in comparison to Persian-speaking participants with distant languages, and surprisingly Persian-speaking participants outperformed French group in word recognition task especially on consistent words. In conclusion, the null hypothesis was rejected.

3) Addressing the Third Research Hypothesis

The third issue addressed whether the L1 had a significant effect upon intermediate and upper intermediate EFL learners' word integration skills. To answer this question, the present researcher tested two groups of participants, namely French and Persian. The result revealed a significant effect for language group, since $(\mathrm{F}=102.914, \mathrm{p}=0.00$ $<0.05)$. Therefore, Persian and French speakers did not process direct objects at the same rate. Additionally, there was a main effect for high context $(\mathrm{F}=116.743, \mathrm{p}=0.00<0.05)$ and low context $(\mathrm{F}=60.698, \mathrm{P}=0.00<0.05)$. The mean values across the two semantic context condition depict (Table 4.11) that the French EFL participants were able to integrate high context and low context direct objects more rapidly than the Persian EFL participants, which is reflected in the overall group means for the French (1416 millisecond) and Persian (1595 millisecond). On the other hand, both group's RT in semantically lower context sentences was lower than high context sentences. Consequently, the null hypothesis was dismissed as a language group $(\mathrm{A} 0=$ Persian/French) main effect was nearly significant since $(\mathrm{p}=0.77>0.05)$. On the other hand, the Iranian participants were significantly slower than French-speaking participants in integrating English words into larger elements such as phrases and clause units of meaning and finally comprehending the high context and low context clauses in an on-line reading comprehension task.

4) Addressing the Fourth Research Hypothesis

The fourth research question explored whether bilingual intermediate and upper intermediate native French-speaking EFL learners with linguistically close native languages (French-English) outperform intermediate and upper intermediate linguistically distant native languages (Persian-English) EFL learners in word integration direct object reading task because of the similarities between both languages in this domain (word integration).

To answer this question, the present author tested two groups of participants, namely French and Persian. Based on the results of the current study, it could be concluded that EFL French-speaking participants who did word integration reading tasks went beyond in comparison to Persian-speaking participants. In other words, they outperformed the Persian group in both stimuli high context and low context. We can make the long story short by stating that the first, second and third null hypotheses of the study were rejected but the third null hypothesis held true.

\section{B. ESL Word Recognition Skills}

In general, although Persian and English are distant languages the speed results from the lexical decision task depicted that the Persian EFL participants were able to process consistent and inconsistent words in a lexical decision task more rapidly than the French EFL participants. These results are supported by 150-ms advantage over the French participants in total. Surprisingly, the main difference in language group by word condition was regarding consistent words as there was an advantage of 206 milliseconds of Persian group over the French group.

Persian which is a vowelized language and has similar characteristics to vowelized Hebrew has an orthography that is transparent for reading but opaque for spelling (Arab-Moghaddam \& Sénéchal, 2001). Furthermore, the Persian language is consistent and as (Arab-Moghaddam \& Sénéchal, 2001) declared, Persian," has very regular grapheme-tophoneme correspondence rules because each grapheme has a single pronunciation (i.e., Persian is not polyphonic)" (p. 142). On the other hand, according to (Decoo, 2001) English language is highly inconsistent and opaque. Based on the previous researchers and evidences, it can be concluded that the similarities between consistency of Persian language and consistent words in English, could be the reason that Persian speakers outperformed French-speakers mainly in consistent words regardless of Persian/Farsi orthographical differences with English. And as (Arab-Moghaddam \& Sénéchal, 2001) declared the "nature of the Persian orthography encourages children to adopt different strategies when reading and spelling words" (p. 142).

Officially, English and Arabic languages are listed as the mandatory high school courses and are included as foreign languages in the public educational system in Iran. English and Arabic languages are added as foreign languages to the system in the first grade in secondary school. Additionally, as it was asserted by (Sadeghi \& Richards, 2016), regarding English, the focus is mainly on alphabet recognition and vocabulary instruction and increasing the range of vocabularies. Consequently, that could be quite likely that Persian-speaking EFL participants' advantage and performance in the lexical decision task over French-speaking participant regardless of orthographic differences between English and 
Persian in the present study, could be the result of word recognition skills developed experiences in primary and secondary schools in Iran which made students strong in the lexical domain.

\section{ESL Word Integration Skills}

In conclusion, based on the research results, there were highly significant differences between direct object reading time of French and Persian EFL groups, as French and Persian groups did not process the direct objects at the same rate. French participants demonstrated, 179ms advantage over the Persian participants in total in reading the high and low semantic context (semantic plausibility) direct objects, $191 \mathrm{~ms}$ across the high context, 168ms across low context semantic conditions .Subsequently, based on the above-mentioned results in the current research it was concluded that both French and Persian groups' direct object reaction time in integrating words into the larger phrase and clause structures and comprehending them was lower in high context and higher in the low context which as (Fender, 2003) acknowledged " the semantic context (i.e., semantic plausibility) effect clearly shows that low context direct objects require more semantic/conceptual processing effort than high context direct objects during incremental word integration processing" (p. 307).

A great number of psycholinguistic researches in both L1 research (Crain \& Shankweiler, 1990; Fodor, Ni, Crain, \& Shankweiler, 1996; Garrett, 2000; Gibson, 1998) and in L2 research (Frenck-Mestre \& Pynte, 1997; Juffs, 1998) depicted that incremental syntactic or structural word attachments into the phrase and clause structures are involved in fluent English word integration processes. Besides as it was acknowledged by (Boland, 1997; Jackendoff, 1997; Mahesh, Eiselt, \& Holbrook, 1999) structural word integration processes are one of the crucial components in incremental word integration procedures that contain and navigates the process of sentence comprehension and establishes syntactic and structural relationships among sentence constituents. Finally, due to word integration results, it can be concluded that French-speaking participants can use more extensive EFL world integration processes than the Persian participants which is supported by $179 \mathrm{~ms}$ advantage over the Persian participants.

Moreover, based on the evidence and results of the current research and as (Fender, 2003; Gass, 1999; Juffs \& Harrington, 1996; Kilborn, 1994) claimed word integration skills and processes in mother tongue (L1) affect L2 word integration processes development specifically during adolescence or later period that people acquire the L2.

Based on the current research results that Persian-speaking participants reaction time was higher than French group and they were slower in word integration task, it can be concluded that although English and Persian are both headinitial languages, Persian language is head-final in VPs(verb phrases and consequently in Persian language learners first process subject and verb and later on the verb that may effect on their word integration time in English which in VP is head initial) as a consequence of L1 structural and syntactic differences in word integration and sentence processing format in the first language of EFL Persian-speaking group and English, and orthographic differences between English and Persian, the Persian group were slower than French group in word integration task. In addition, the Persian language writing Style is from right to left and can be inferred that reading the English sentences on the display will take longer, because it is an incongruent activity due to the orientation of the sentences which could be the explanation for their higher RT in direct object reading.

In addition, it can also be inferred that, as in Iran's English education system, the emphasis is primarily on increasing the repertoire of vocabulary and, as reported by (Sadeghi \& Richards, 2016), in high school, the attention shifts mainly to reading comprehension, which may result in poor reading skills due to lack of a clear emphasis on reading skills from early elementary schools.

\section{CONCLUSION}

As a finding in the present study, based on the results of ANCOVA, typically speaking the pace resulting from the lexical decision task indicated that the Persian EFL participants were able to interpret consistent and inconsistent words faster than the French EFL participants, while Persian and English are orthographically and typologically distant languages. Surprisingly, the main difference by word condition was regarding consistent words. As (Arab-Moghaddam \& Sénéchal, 2001) asserted, the Persian language is a transparent and consistent language that each grapheme corresponds to a single phoneme (i.e., Persian is not polyphonic).Accordingly this could be the explanation why Persian speakers outperformed French-speakers in the word recognition task especially regarding consistent words.

Moreover, in the public education system in Iran, the emphasis is primarily on the identification of alphabets and vocabulary teaching, and on growing the variety of vocabulary that may be very possible for Persian-speaking EFL participants to acquire fairly high English word identification skills owing to the comprehensive vocabulary activities in their education system. In other words, it can be mentioned that this superiority and success in lexical decision-making tasks over French-speaking participants, irrespective of the orthographic variations between English and Persian, maybe the product of orthographic skills acquired in primary and secondary schools in Iran. It allows students strength in the lexical sector.

Another issue explored in this study was whether there was any difference between word integration skills of typologically distant and close languages. Consequently, very significant differences have arisen based on methodological procedures. French participants showed superiority over Persian participants in the direct object reading time in both semantically high context and low context sentences. Subsequently, it was hypothesized that the direct 
object reading response time of both the French and Persian groups, incorporating and interpreting terms into the broader phrase and clause systems, was lower in a high context, which goes in line with a research by (Fender, 2003)" the semantic context (i.e., semantic plausibility) effect clearly shows that low context direct objects require more semantic/conceptual processing effort than high context direct objects during incremental word integration processing" (p. 307). In conclusion, text semantic ambiguity may affect the success of EFL learners, irrespective of their mother tongue, and typological similarities or differences between L1 and L2 (Fender, 2003).

In analyzing the results of the ANCOVA study, the researcher was able to infer that there was a positive relationship between EFL learners' word integration skills and their L1. As a consequence, it is undisputed that word integration skills and processes in the mother tongue (L1) have affected the creation of L2 word integration processes especially during puberty or later times when people learn L2 (Fender, 2003; Gass, 1999; Juffs, 1998; Kilborn, 1994). The result of the present study emphasizes the positive effects of first language interference in second or foreign language acquisition as due to syntactic similarities between French and English, French speakers outperformed in the process of word integration task which is in line with (Hakuta \& McLaughlin, 1996b) research result that the first language may provide a detrimental or positive transition (facilitation) to the second language, where the structure of the two languages is specific, there is a negative transfer (interference), and where the structure of the two languages is identical, there is a positive transfer (facilitation) and L1 promotes the acquisition of L2 (Hakuta \& McLaughlin, 1996b).

\section{REFERENCES}

[1] Aquil, R. (2012). L1 shapes L2 auditory representation elicited imitation of Arabic-speaking learners of English. International Journal of Applied Linguistics and English Literature, 1(1), 39-63.

[2] Arab-Moghaddam, N., \& Sénéchal, M. (2001). Orthographic and phonological processing skills in reading and spelling in Persian/English bilinguals. International Journal of Behavioral Development, 25(2), 140-147.

[3] Bates, E. (1999). Processing complex sentences: A cross-linguistic study. Language and Cognitive Processes, 14(1), 69-123.

[4] Bhatia, T. K., \& Ritchie, W. C. (2008). The handbook of bilingualism. Malden, MA: Blackwell.

[5] Boland, J. E. (1997). The relationship between syntactic and semantic processes in sentence comprehension. Language and Cognitive Processes, 12(4), 423-484.

[6] Burchfield, R. W., \& Burchfield, R. (1985). The English Language. Oxford: Oxford University Press

[7] Crain, S. \& Shankweiler, D. (1990). Exploring failure in spoken language comprehension by children with reading disabilities. In D. Balota, G. Flores d'Arcais, K. Rayner (Eds.). Comprehension processes in reading (pp. 539-555). Hillsdale, NJ: Erlbaum.

[8] Crystal, D. (2012). English as a global language. Cambridge: Cambridge university press.

[9] Decoo, W. (2001). On the mortality of language learning methods. Forum article on the DIDASCALIA web site. Retrieved February 8, 2006, from http://www.didasca lia.be/mortality.htm.

[10] Dooey, P. and Oliver, R. (2002). An investigation into the predictive validity of the IELTS test as an indicator of future academic success. Prospect, 17(1), 36-54.

[11] Fender, M. (2001). A review of L1 and L2/ESL word integration skills and the nature of L2/ESL word integration development involved in lower-level text processing. Language Learning, 51(2), 319-396.

[12] Fender, M. (2003). English word recognition and word integration skills of native Arabic-and Japanese-speaking learners of English as a second language. Applied Psycholinguistics, 24(2), 289-315.

[13] Field, A. (2016). An adventure in statistics: The reality enigma. London: Sage.

[14] Fodor, J. D., Ni, W., Crain, S., \& Shankweiler, D. (1996). Tasks and timing in the perception of linguistic anomaly. Journal of Psycholinguistic Research, 25(1), 25-57.

[15] Frenck-Mestre, C., \& Pynte, J. (1997). Syntactic ambiguity resolution while reading in second and native languages. The Quarterly Journal of Experimental Psychology A, 50(1), 119-148.

[16] Frost, R., Katz, L., \& Bentin, S. (1987). Strategies for visual word recognition and orthographical depth: a multilingual comparison. Journal of Experimental Psychology: Human Perception and Performance, 13, 104-115.

[17] Garrett, M. (2000). Remarks on the architecture of language processing systems. In Language and the brain (pp. 31-69): Elsevier.

[18] Gass, S. (1999). Discussion: Incidental vocabulary learning. Studies in second language acquisition, 21(2), 319-333.

[19] Gibson, E. (1998). Linguistic complexity: Locality of syntactic dependencies. Cognition, 68(1), 1-76.

[20] Grabe, W. (1988). Reassessing the term "interactive". Interactive approaches to second language reading, 6, 56-70.

[21] Grabe, W. (1991). Current developments in second language reading research. TESOL quarterly, 25(3), 375-406.

[22] Gu, P. Y. (2003). Fine Brush and Freehand 1: The Vocabulary-Learning Art of Two Successful Chinese EFL Learners. TESOL quarterly, 37(1), 73-104.

[23] Hakuta, K., \& McLaughlin, B. (1996b). Seven tensions that define research on bilingualism and second language acquisition. The handbook of educational psychology. Washington, DC: American Psychological Association.

[24] Inoue, M. (1996). Kaosu to fukuzastukei no kagaku [Science of chaos and complexity]. Tokyo: Nihon Jistugyo

[25] Jackendoff, R. (1997). The architecture of the language faculty: MIT Press.

[26] Juffs, A. (1998). Main verb versus reduced relative clause ambiguity resolution in L2 sentence processing. Language Learning, 48(1), 107-147

[27] Juffs, A., \& Harrington, M. (1996). Garden path sentences and error data in second language sentence processing. Language Learning, 46(2), 283-323.

[28] Just, M. A., \& Carpenter, P. A. (1980). A theory of reading: From eye fixations to comprehension. Psychological review, 87(4), 329.

[29] Kellerman, E. (1986). An eye for an eye: Crosslinguistic constraints on the development of the L2 lexicon. Crosslinguistic influence in second language acquisition, 35-48. 
[30] Kilborn, K. (1994). Learning a language late: Second language acquisition in adults. Handbook of psycholinguistics, 917-944.

[31] Koda, K. (2000). Cross-linguistic variations in L2 morphological awareness. Applied Psycholinguistics, 21(3),297-320.

[32] Mahesh, K., Eiselt, K. P., \& Holbrook, J. K. (1999). Sentence processing in understanding: Interaction and integration of knowledge sources. In Understanding language understanding: Computational models of reading (pp. 27-72).

[33] McDonald, J. L. (2000). Grammaticality judgments in a second language: Influences of age of acquisition and native language. Applied Psycholinguistics, 21(3), 395-423.

[34] Mokhtari, R. (2014). The Comparative Study of Literary vs. Nonliterary Text and Iranian EFL Learners' Performance on Cloze Tests of Inference. Journal of Language Teaching \& Research, 5(1).

[35] Nation, P. (2003). The role of the first language in foreign language learning. Asian EFL Journal, 5(2), 1-8.

[36] Odlin, T. (1989). Language transfer: Cross-linguistic influence in language learning. Cambridge: Cambridge University Press.

[37] Sadeghi, K., \& Richards, J. C. (2016). The idea of English in Iran: An example from Urmia. Journal of Multilingual and Multicultural Development, 37(4), 419-434.

[38] Schachter, J. (1983). A new account of language transfer. Language transfer in language learning, 2, 98-111.

[39] Turker, D. \& Selcuk, S.S. (2009). Which factors affect entrepreneurial intention of university students? Journal of European Industrial Training, 33(2), 142-159.

[40] Zu, F.-X. (2009). Using lexical approach to teach vocabulary. US-China Foreign Language, 7(8), 44-47.

Nazanin Biglari received her bachelor's degree in English language and literature in 2012. She finished her master studies in TEFL in Iran and received her master after master in Linguistics and Literary studies (Multilingualism and Foreign Language Acquisition) from the Vrije Universiteit Brussel (VUB), Belgium.

Esli Struys is a professor of Multilingualism at the Vrije Universiteit Brussel in Belgium where he has taught courses on psychoand neurolinguistics, language and multilingual education, multilingualism and cognition, and interpreting studies. He is the head of an international research team in the domains of multilingual education and cognition. 